\title{
Language description and use
}

\section{DESCRIPTIVE STUDIES OF PARTICULAR LANGUAGES ENGLISH}

84-319 Everaert, Martin (U. of Utrecht, The Netherlands). A syntactic passive in Dutch. Utrecht Working Papers in Linguistics (Utrecht), 2 (1982), 37-62.

Certain dynamic double object constructions in Dutch like [hij werd de keus gelaten/ he was given the choice], can be accounted for syntactically, without assuming the operation of a transformation involving noun phrase movement. Constructions like *[hij werd het boek gegeven / he was given the book], are ungrammatical, however.

Following Chomsky (1981), the author proposes a modification of the caseassignment rules that allow a dative case to become nominative during passivisation, to explain these indirect object passives. This would also account for Accusativecum-Infinitive constructions like [fan liet het boek kopen / John had the book bought (lit. 'buy)]. The range of syntactic passives extends to idiomatic NPs which escape the case-filter, viz. [hij werd de les gelezen / he was read the lesson], object clauses, which are insensitive to the case-filter, viz. [wij werden verzocht weg te gaan / we were asked to leave] and direct objectless passives.

Since a lexicalist analysis cannot account for these constructions satisfactorily, they constitute corroborative evidence for the transformationalist position in the lexical versus transformational passive debate.

84-320 Bansal, R. K. (CIEFL, Hyderabad). English and Hindi: a contrastive phonological study. CIEFL Bulletin (Hyderabad, India), 17, 2 (1981), 51-60.

A contrastive phonological analysis between English and Hindi takes into account the phonetic characteristics of the sounds, the phonemic systems, the syllabic structures, and prosodic features like length, stress and pitch. Both English and Hindi belong to the Indo-European family of languages and have much in common. The varieties chosen for the study are Received Pronunciation and Standard Hindi. Some differences highlighted are that Hindi has 10 pure vowels of which two can be diphthongised; English has 12 pure vowels and 8 diphthongs. Hindi has 20 plosive phonemes, English six and two affricates. The rules of vowel length are different in the two languages. In orthography, Hindi has a much closer correspondence between the phonemes and the letters used to represent them than English has. Word accent in English often depends on the derivation, morphemic structure and grammatical function of the word; in Hindi it depends on syllabic structure. The rules of assimilation at word boundaries are different in Hindi and English. Elision is a feature in both languages but the patterns are different, likewise the patterns of accentuation and rhythm in connected speech, and the patterns of intonation. 
84-321 Egbe, Daniel I. (U. of Lagos). Aspects of English grammar and usage. Papers in Linguistics (Champaign, III), 14, 2 (1981), 271-96.

The semantic, rhetorical and stylistic potentials of the English words but and except are examined in the light of English usage which is seen to be inseparable from the grammar itself. On the whole, this analysis points out the closeness and complexity of the relationship between syntax and semantics in a natural language. In particular, but demonstrates the ability not only to link syntactic structures in subtle ways but also to convey various ideas, attitudes, moods and feelings, including those that are not overtly expressed. Of particular significance is the dependence of the two words (but and except) on extralinguistic factors to introduce clauses and phrases which otherwise would seem out of context in a discourse. Thus, in their various functions, both words go beyond their basic dictionary meanings. General usage, therefore, captures those resources of language to which it is difficult to give lexical definitions.

84-322 King, Larry D. (U. of North Carolina). The semantics of tense, orientation, and aspect in English. Lingua (Amsterdam), 59, 2/3 (1983), 101-54.

A strict separation is drawn between semantics and pragmatics in order to define tense, orientation, and aspect as three semantic notions of the verb governed by external speaker viewpoint on real world phenomena. Invariants of grammatical meaning are posited for English simple, progressive, and perfect forms, and it is shown that all forms must be defined by a feature of each semantic notion. Argumentation is given to support the one form/one meaning interpretation of abstract semantic structure, and evidence is provided to suggest that this characterisation of semantics allows for a more disciplined approach to the consideration of universal principles in systematic semantics.

84-323 Kirk, John $M$. (U. of Sheffield). On Scottish non-standard English. Nottingham Linguistic Circular (Nottingham), 10, 2 (1981) [publ. 1983], 155-78.

The definitions of Scottish Standard English and Scottish non-standard English are reviewed and are shown to be functional abstractions embracing several subvarieties identified, like the varieties of English, by criteria based on a mixture of social snobbery and linguistic mythology, which frequently nullify the serious linguistic analysis of such scholars as Aitken and Macafee, e.g. socially 'Bad Scots' turns out to be linguistically 'Good Scots'.

To escape this impasse, the underlying syntactic types are studied and the relationship between standard and non-standard diagnosed. Within the system of Scots English, the regular differences between the standard and non-standard are structural. This is concluded on the basis of literary written samples. These grammatical differences represent optional ways of contrasting, foregrounding, emphasising and deleting elements of the underlying sentence. The optional availability of as much Scots as a speaker may wish to avail his speech of is the most distinctive characteristic of Scottish non-standard English, since a speaker has access to a rich fund of historical Scots. Otherwise, it is merely a parallel to the standard core in the 
same way as other non-standard dialects in Britain are. The author is to survey a corpus of dramatic writing in this dialect.

\section{ESPERANTO}

84-324 Chin-chuan Cheng. The Esperanto of 'El Popola Cinio'. Studies in the Linguistic Sciences (Urbana-Champaign, III,), 12, 1 (1982), 49-62.

The use of Esperanto in China since the turn of the century has cast Chinese elements on to Esperanto to reflect cultural characteristics. From the writings of the monthly magazine El Popola Cinio, Chinese innovations, especially those belonging to word formation and idioms, are identified. On the basis of the findings, the relationships between international norm and local variation are discussed.

84-325 Sherwood, Bruce Arne. Statistical analysis of conversational Esperanto, with discussion of the accusative. Studies in the Linguistic Sciences (Urbana-Champaign, III), 12, 1 (1982), 165-82.

Taped Esperanto conversations among skilled speakers were transcribed and statistically analysed. The frequencies of phonemes, two-phoneme sequences, and grammatical categories were obtained. Statistics on the use of compound and derived words are presented. The most interesting data deal with the use of the accusative.

Spoken Esperanto is dominantly SVO. Other constituent orders are quite rare and restricted to special constructions. There is a discussion of the sociololinguistic and language-planning consequences of the observed accusative usage.

84-326 Sherwood, Bruce Arne. Variation in Esperanto. Studies in the Linguistic Sciences (Urbana-Champaign, III), 12, 1 (1982), 183-96.

Questions are often raised about the mutual intelligibility of Esperanto spoken by people with different first languages, and about the likelihood of Esperanto splitting into mutually unintelligible dialects if it were used on a wide scale. An attempt is made to describe and explain the present situation, and speculations about the future are also made. Important factors to be taken into account are the nature of the Esperanto speech community; the ways in which vocabulary growth is controlled; pronunciation norms; and phonological and morphological aspects.

\section{FRENCH}

84-327 Colson, Jacques ( $U$. of Alberta). Co-ordination, subordination et fonctions du langage. [Co-ordination, subordination and language functions.] Cahiers de IInstitut de Linguistique de Louvain (Louvain, Belgium), 8, 1/2 (1982), 125-44.

The distinction between co-ordination and subordination is a matter of degree, to be interpreted in the light of syntactic, logico-semantic and pragmatic criteria (all of which interact in various ways [examples]). Pure co-ordination (certain uses of $e t$ ) 
permits syntactic inversion of the constituent clauses without change of meaning or of implication; the co-ordinated elements are structurally parallel (with elision of repeated terms). Certain co-ordinated clauses, however, cannot be inverted because of logical constraints (e.g. where $e t=$ 'and then', 'and so'...). Co-ordinators can also join together clauses that are structurally parallel or whose rhetorical functions are not equivalent; car is a case in point.

Similarly, pure subordination involves the embedding of a clause within a clause (possibly recursively); adverbial clauses, as a typical case, modify the whole matrix clause much as would the adverbs to which their subordinators are semantically related. There are, however, cases in which the adverbial is more loosely related to the main clause; here the adverbial is seen as having a metalinguistic function (Jakobson), in which the speaker justifies the content of his utterance and/or the fact of his uttering it by reference to the conditions (Austin, Searle) that permit an illocutionary interpretation (e.g. Si tu veux à boire, il y a de la bière dans le frigidaire/sers-toi).

84-328 Delbecque, N. (U. of Leuven). Les mots charnières: fréquence et fonction. [Link words: frequency and function.] ITL (Louvain, Belgium), 59 (1983), 55-97.

This paper is a first attempt at a description of link words such as et (and), alors (then), or (now) which are the joints which hold together the structure of discourse. Seven hours of conversational data (of discussions) were analysed to ascertain the frequency and characteristic use of 5 such words : alors, donc, puis (all variants of then), mais (but) and or and the frequencies are also compared with other corpora. Mais is most frequent, whereas in the other spoken corpora alors occurs most frequently. It is argued that this is because the participants are discussing, rather than telling stories, where alors and puis would be used to indicate temporal segments. Donc has a low frequency in spoken discourse and a much higher one in written French. The semantic value of these link words is discussed and compared, with the aid of dictionary entries.

It is concluded that alors is the most semantically neutral link word. [Appendices give a sample of data and analysis.]

84-329 Rapp, Linda Loretto (Indiana U.). French in the New World: linguistic response to cultural patterns. Language Problems and Language Planning (Berlin, FRG), 7, 1 (1983), 1-20.

The aim is (1) to trace the historical role of the French and the French language in the Americas, and (2) to assess the contemporary socio-linguistic situation. Under (1) the author examines settlement and migration patterns of francophones to and in the New World, and considers such extralinguistic facts as the political circumstances in which the settlers found themselves and the influence of the economic structure on the composition and organisation of their communities. The question of the time-depth of direct communication with and official ties to metropolitan France is also important, as is the influence of non-francophone groups with which the French had contact. In this last regard, the interaction of French planters and African slaves, which led to the development of creole dialects, is an especially important issue.

In considering the present status of French and French-based dialects in the 
Americas, three topics arise. (1) The demographic aspect; it is necessary to study where the speakers live, what French dialect they speak, and what other dialects they and their neighbours use. Since francophone communities exist all the way from Canada to the northern coast of South America, and since the members of these communities come from all levels of the socioeconomic spectrum, there is no one typical sociolinguistic pattern. (2) The question of the perception of the dialects by the speakers, their neighbours, and their government must be confronted. The attitude of each of these groups determines not only the number and variety of contexts in which the dialect is routinely used, but also the social and political message one sends by choosing a certain mode of speech. (3) The issue of education and language maintenance - especially in the Caribbean, illiteracy has been and continues to be a serious problem. To overcome it, the transition must be made from a purely oral tradition to one that includes written materials and then the language must be integrated into the educational curriculum. Even where a written tradition exists, it is necessary to maintain its vitality, especially in areas where the French dialect is a minority language.

84-330 Wilmet, Marc (U. of Brussels). Les déterminants du nom en français: essai de syntt :èse. [Nominal determiners in French: an overview.] Langue Française (Paris), 57 (1983), 15-23.

A great deal has been written about the noun and its various determiners: the broad trends are traced and each classification described is acknowledged to have some major default. The analysis presented here takes a very broad definition of the class of determiners as encompassing all those elements which can modify a noun (i.e. using a different terminology, all the constituents of a (non-complex) NP except the noun itself). The various determiners are described, and classified into types. From the analysis it is argued that in fact all the constituents of the noun phrase share one unitary function: that of circumscribing the extension and the 'extensivity' (= quantity) of the noun. This unitary function is termed 'determination' and all words or phrases which can assume it are thence termed 'determiners'.

\section{GERMAN}

84-331 Ballmer, Thomas T. and BrennenstuhI, Waltraud (U. of Bochum). Zum Adverbial- und Adjektivwortschatz der deutschen Sprache. [On the adverb and adjective vocabulary of German]. Linguistische Berichte (Wiesbaden, FRG), 78 (1982), 1-32.

In investigating the adjective and adverb vocabulary of German, the authors advocate the systematic study of large quantities of data based on speaker competence. Using the model of an earlier study of German verbs, they classify the 13,000 adverbs and adjectives found in Wahrig's dictionary into categories according to 'dimensions' of meaning (e.g. hier = 'place'; kalt $=$ 'temperature'). A total of 660 categories are recognised, of which some can be ordered hierarchically according to implicational 
relations. These categories are grouped into 47 general areas of meaning (e.g. 'quantity', 'movement') which are in turn collected into 13 main groups (e.g. 'presupposing events', 'presupposing objects'). The groups and areas are listed in full, and examples are given of a number of the categories ('emotion, 'time', 'action', 'size') with some details of their finer structure. The resulting classification is compared with those of Curme and the Duden grammar, which are found to be unbalanced and incomplete.

84-332 Haftka, Brigitta. Thesen zu Prinzipen der deutschen Wortstellung. [Theses on the principles of German word order.] Deutsch als Fremdsprache (Leipzig, GDR), 19, 4 (1982), 193-202.

German word order is difficult to describe because the syntacto-hierarchical and communico-pragmatic principles work closely together in the German sentence. Taking idealised basic strings as examples, it appears that the closer the syntactic link between the verb and an element in the predicate, the more that element is displaced towards the end of the sentence and hence the further it is from the finite verb. The members of the predicate group in the narrow sense, especially the finite verb, have a relatively fixed position. Variants from this position can therefore carry specific rhetorical effects. In particular, as detailed examples and diagrams show, variation largely depends on consideration of known/unknown information as between speaker and hearer, and given/new elements in the discourse. The selection from their possible permutations permits the identification of theme and rheme almost independently of the speaker's own intention.

\section{SPANISH}

84-333 Borzone de Manrique, Ana María and Signorini, Angela (U. Católica Argentina). Segmental duration and rhythm in Spanish. Journal of Phonetics (London), 11, 2 (1983), 117-28.

The study of some temporal aspects of Argentine Spanish is undertaken in order to provide experimental evidence about the nature of Spanish rhythm, which has been considered syllable-timed. The duration of vowels, consonants and syllables under different conditions of stress and position, and inter-stress intervals was measured.

Results show that segment duration varies according to several factors, contrary to the assumption that Spanish syllables are similar in duration. Inter-stress intervals are found to cluster around an average value and some modifications of segment duration are observed in order to achieve more regular intervals. The analysis of all these data, together with a consideration of the phonetic nature of stress, leads to the conclusion that Spanish rhythm has a tendency to stress alternation. 


\section{RUSSIAN}

84-334 Katlinskaya, L. P. (Moscow). Живые способы создания новых слов. [Productive means of creation of new words.] Русский язык в национальной иколе (Moscow), 1 (1983), 9-13.

An outline is given of the ways in which new words are created on the basis of existing patterns of word formation; these characterise a set of 'potential words', only some of which are used regularly enough to gain entry to dictionaries. As an example of this type of neologism, words with the prefix co- in Russian are analysed, constructed either on the basis of the meaning of joint action or state (e.g. coasmop 'co-author') or with a meaning of unification (e.g. совозрастник 'person of the same age group').

\section{TRANSLATION/INTERPRETING}

84-335 Kotov, R. G. and others. Машинный перевод в начале 80-х годов. [Machine translation in the '80s.] Вопросы языкознания (Moscow), 1 (1983), 31-8.

On the basis of actually working machine translation systems, the prospects for linguistic developments in machine translation are considered. A number of general patterns are noted - the lack of success of semantically based machine translation systems, the relative ineffectualness of systems based on enumeration of all possible interpretations of elements and the greater worth of systems based on the recognition of whole patterns, the need to make a principled distinction between the linguistics and the processes based on it, rather than simply taking any explicit system. There is also brief consideration of the need to study human translation, and of the need for information relating to real world knowledge, frequency of patterns, etc.

84-336 Lederer, Marianne (U. Paris XII). Le processus de la traduction simultanée. [The process of simultaneous interpretation.] Multilingua (Amsterdam), 1/3 (1982), 149-58.

Broadly speaking, the process of simultaneous interpretation can be broken down into three phases, of which the first two, perception and conceptualisation, are amongst the most natural and frequent of all phenomena, while the third, expression, encounters such constraints that it becomes almost an unnatural act.

The interpreter perceives sounds like any other listener, and like him reconstitutes them rather than hears them. Like any other listener he conceptualises the message carried by the words uttered, and as in the case of any other listener, certain elements in the speech are registered by his memory whilst others fuse into a syncretic conceptual unit.

During the expression phase, on the other hand, not only does the interpreter discover the ideas which he must express virtually at the same time as he translates them, but he is also hindered by the form of the original language. To overcome these constraints he formulates his speech sometimes minimising the time-lag between 
himself and the speaker, in which case he can transcode, and sometimes letting the speaker run ahead, in which case he can formulate without servility. In either event his speech is parallel speech, based on the original without being its carbon copy, sometimes inspired improvisation and sometimes strict terminological transposition.

\section{LEXICOLOGY}

84-337 Carter, Ronald (U. of Nottingham). A note on core vocabulary. Nottingham Linguistic Circular (Nottingham), 11, 2 (1982), 39-47.

There are several reasons why some vocabulary items should be more 'core' or basic than others to the expression of meaning. There needs to be some neutral norm or unmarked set of features, otherwise degrees of expressivity would be impossible to perceive, nor could deviation be measured. Languages require resources of simplified yet clearly comprehensible communication for such tasks as talking to children and foreigners, summarising, etc. Criteria for identifying core vocabulary are suggested: (1) it has a wide collocational span, partnering a broad range of other items within different contexts (e.g. fat collocates with man, chicken, salary, book, hence fat is core while obese is not); (2) it is more neutral or unmarked than other items and is only rarely used to communicate affective meaning.

Informants were used for a case-study of words for thin in English: they were asked to rate thin and a range of words from a related set along separate scales for evaluation, formality, and intensity. Thin came out at the middle of the scales. Another test aimed to demonstrate that core vocabulary items cannot easily be defined with reference to non-core items. Superordinates can sometimes be core vocabulary items. Many lexical items which are intuitively felt to be core words can easily be found an antonym (thin $\leftrightarrow f a t ;$ walk $\leftrightarrow$ run).

The two main arguments for a cognitive basis for core vocabulary relate $(a)$ to the conceptual organisation of the universe being carried through into the structural organisation of the vocabulary, and $(b)$ to the division between conceptual (stable) and associative (relative) meaning; linguistic semantics aims to define conceptual meaning by the creation of a theoretical or conceptual dictionary which accounts in full for a native speaker's semantic competence, but without reference to practical usage.

Some of the main problems with the definition of core and non-core words concern words with a wide collocational range, and specialised fields of discourse. A more precise definition of core vocabulary should be of benefit in a number of areas of foreign-language learning and teaching, design of dictionaries, and the design of simplified readers.

84-338 Meara, Paul (Birkbeck Coll., U. of London). Word associations in a foreign language: a report on the Birkbeck Vocabulary Project. Nottingham Linguistic Circular (Nottingham), 11, 2 (1982), 29-38.

Word associations produced by native speakers are highly predictable; learners' responses are more varied, despite their limited vocabulary, because they tend to 
produce 'clang' associations (related to the stimulus phonetically but not semantically) like young children; they also frequently misunderstand the stimulus word, even when the word is simple and they claim to know it. The data suggest that the semantic links between words in the learner's mental lexicon are fairly tenuous. The theoretical models for word-association behaviour in a second language are unsatisfactory, probably because too little consideration has been given to what words should be chosen as stimuli. The use of standard lists of stimuli (e.g. the Kent-Rosanoff list) ought to make it possible to obtain comparisons between the responses of native speakers and those of learners, but unfortunately the high-frequency words used tend to produce very similar responses in both the target and native language. Moreover, because they are high-frequency words, they are among the first words a learner acquires in his L 2, when acquisition patterns are likely to differ from what happens when more fluent speakers learn words. This makes it difficult to study the area of greatest interest, i.e. the periphery of a learner's vocabulary - how new words are acquired and integrated.

More interesting topics are the instability of learners' associations, what happens to new words as they are acquired (some kind of complex absorption can be seen to occur), and what can be deduced from obvious errors in word association tests about the way words are stored and handled by learners.

\section{INFORMATION RESOURCES}

84-339 Dewezé, A. (Documentation Service, Grenoble). Documentation scientifique et technique: problèmes de multilinguisme-notion de réseau sémantique. [Scientific and technical documentation: problems of multilingualism - semantic networks.] Bulletin CILA (Neuchâtel), 37 (1983), 46-62.

A description of the working procedures of a commercial documentation service is given: cataloguing, abstracting and indexing by key words. With the aim of working towards an eventual automatic indexing procedure, the authors describe the way in which lexical relations (e.g. polysemy, synonymy) and semantic and pragmatic relations are important in indexing. Mismatches in polysemy between the main European languages cause problems for indexing in several languages. An example of automatic indexing is given. 